\title{
Aorta-bal kamra tunnel sikeres sebészi kezelése modern noninvazív képalkotó diagnosztika alapján
}

\author{
Hartyánszky István dr. ${ }^{1}$ - Katona Márta dr. ${ }^{2}$ - Kádár Krisztina dr. ${ }^{4}$ \\ Apor Asztrid dr. ${ }^{4}$. Varga Sándor dr. ${ }^{1}$. Simon Judit dr. ${ }^{3}$. Tóth Attila dr. ${ }^{4}$ \\ Karácsony Tünde dr. ${ }^{5}$ - Bogáts Gábor dr. ${ }^{1}$ \\ Szegedi Tudományegyetem, Szent-Györgyi Albert Orvostudományi Központ, ${ }^{1}$ Kardiológiai Központ, \\ Szívsebészeti Osztály, ${ }^{2}$ Gyermekgyógyászati Klinika, ${ }^{3}$ Aneszteziológiai és Intenzív Terápiás Intézet, Szeged \\ ${ }^{4}$ Semmelweis Egyetem, Általános Orvostudományi Kar, Városmajori Szív- és Érgyógyászati Klinika, Budapest \\ ${ }^{5}$ Hajdú-Bihar Megyei Kenézy Gyula Kórház, Debrecen
}

\begin{abstract}
Az aorta-bal kamra tunnel egy ritka veleszületett szívfejlődési rendellenesség, az aortabillentyưt megkerülő kóros kapcsolat az aorta és a bal kamra között. A szerzők egy 14 éves fiú esetét ismertetik, akinél a jobb Valsalva-tasakban, az eredésénél pericardiumfolttal zárták a tunnelt. A kétdimenziós echokardiográfiás anatómiai diagnózist háromdimenzios vizsgálattal egészítették ki és mágneses rezonanciavizsgálattal erősítették meg. Esetük az első az irodalomban, amelynél a fenti komplex diagnosztikát alkalmazták a pre- és posztoperatív kezelés során. Az újonnan alkalmazott transthoracalis háromdimenziós módszerrel optimalizálható az aorta-bal kamra tunnel anatómiai és hemodinamikai diagnosztikája és posztoperatív utánkövetése. Orv. Hetil., 2015, 156(28), 1140-1143.
\end{abstract}

Kulcsszavak: aorta-bal kamra tunnel, 3D echokardiográfia

\section{Successful surgical management of aortico-left ventricular tunnel using modern noninvasive diagnostic imaging methods}

\begin{abstract}
Aortico-left ventricular tunnel is a rare congenital cardiac defect, which bypasses the aortic valve via the paravalvar connection from the aorta to the left ventricle. The authors report the history of a 14-year-old boy with aortico-left ventricular tunnel in whom the aortic orifice arose from the right aortic sinus and was closed by a pericardial patch. The diagnosis was confirmed by combined two-dimensional and real time three-dimensional echocardiogram and magnetic resonance imaging. This is the first case, in which these complex diagnostic imaging methods have been used in the pre- and postoperative management of this defect. Optimally the new transthoratic three-dimensional echocardiography would be needed to define the anatomy and functional consequences of the aortico-left ventricular tunnel and in the postoperative follow-up.
\end{abstract}

Keywords: aortico-left ventricular tunnel, real time three-dimensional echocardiogram

Hartyánszky, I., Katona, M., Kádár, K., Apor, A., Varga, S., Simon, J., Tóth, A., Karácsony, T., Bogáts, G. [Successful surgical management of aortico-left ventricular tunnel using modern noninvasive diagnostic imaging methods]. Orv. Hetil., 2015, 156(28), 1140-1143.

(Beérkezett: 2015. április 28.; elfogadva: 2015. május 21.)

\section{Rövidítések}

Ao $=$ aorta $; \mathrm{BKD}=$ balkamra-diasztolé; $\mathrm{BKF}=$ balkamra-fal; $\mathrm{Bp}=$ bal pitvar; $\mathrm{CT}=$ komputertomográfia; $3 \mathrm{D}=$ háromdimenziós; 3DE = háromdimenziós echokardiográfia; IVS = in- terventricularis septum; lin. $\mathrm{EF}=$ lineáris ejekciós frakció; $\mathrm{MR}=$ mágneses rezonancia; $\mathrm{TEE}=$ transoesophagealis echokardiográfia 

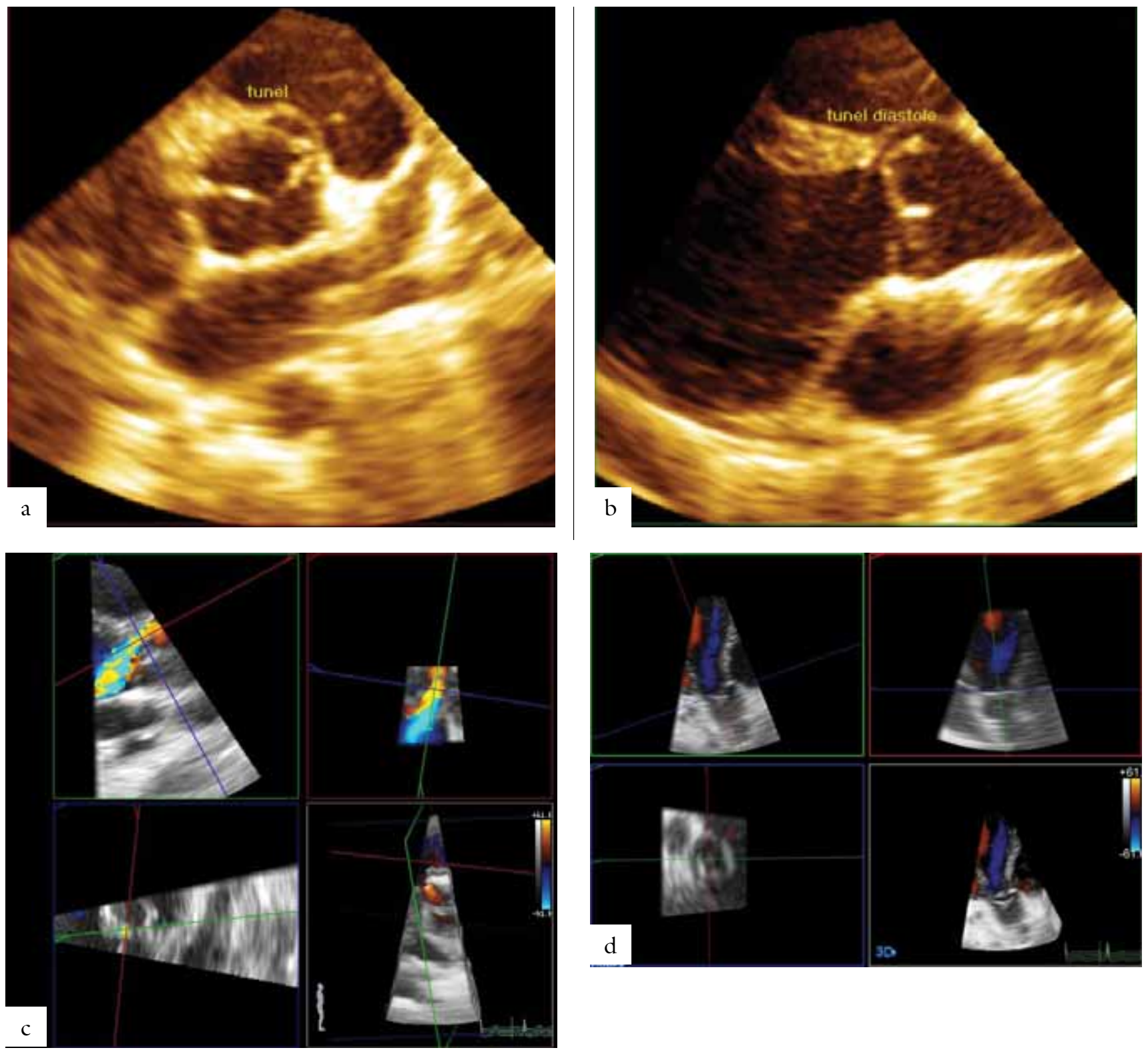

1. ábra

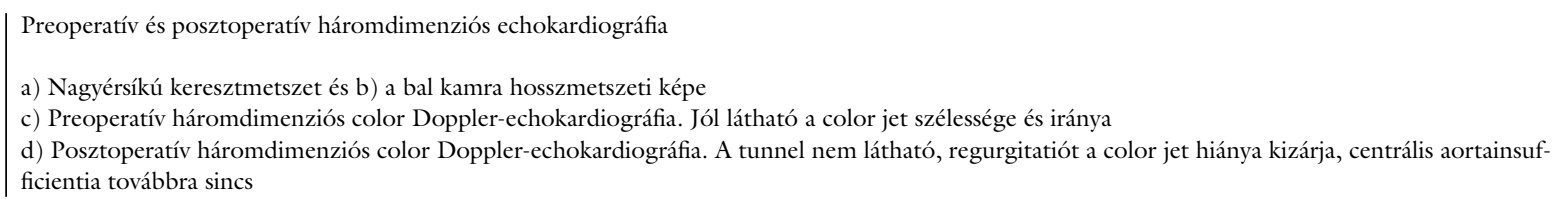

Az aorta-bal kamra tunnel egy kóros endothelizált paravalvularis kapcsolat az aortagyök és a bal kamra között. Ritka fejlődési rendellenesség, egy ezreléke az élve született szívbetegeknek. 1963-ban Levy és mtsai [1] ismertették az első eseteket, azóta körülbelül 130 betegről számoltak be az irodalomban.

\section{Esetismertetés}

A 14 éves fiú négy éve állt kardiológiai gondozás alatt aortainsufficientia diagnózis miatt. Fizikális vizsgálatából jó általános állapot, kompenzált keringés mellett intenzív

praecordialis pulzáció, ritmusos szívmúködés, punctum maximummal a bal parasternalis III-ban 1/6-os szisztolés ejekciós és hangos protodiasztolés zörej emelendő ki. Mellkasröntgenen a szív nem volt nagyobb, a pulmonalis ív kissé elődomborodott, a tüdők tiszták voltak. Vérnyomása 128/53 Hgmm volt.

Transthoracalis echokardiográfiás vizsgálattal a morfológiai kép alapján aorta-bal kamra tunnelt diagnosztizáltunk. A tunnel a jobb coronariás tasak előtt irányult a bal kamra ürege felé, szélessége, illetve az ezen megnyilvánuló regurgitatio és bal kamrai tágasság progressziót mutatott (tág bal kamra, BKD: 55/35 mm, lin. EF: 0,4, 

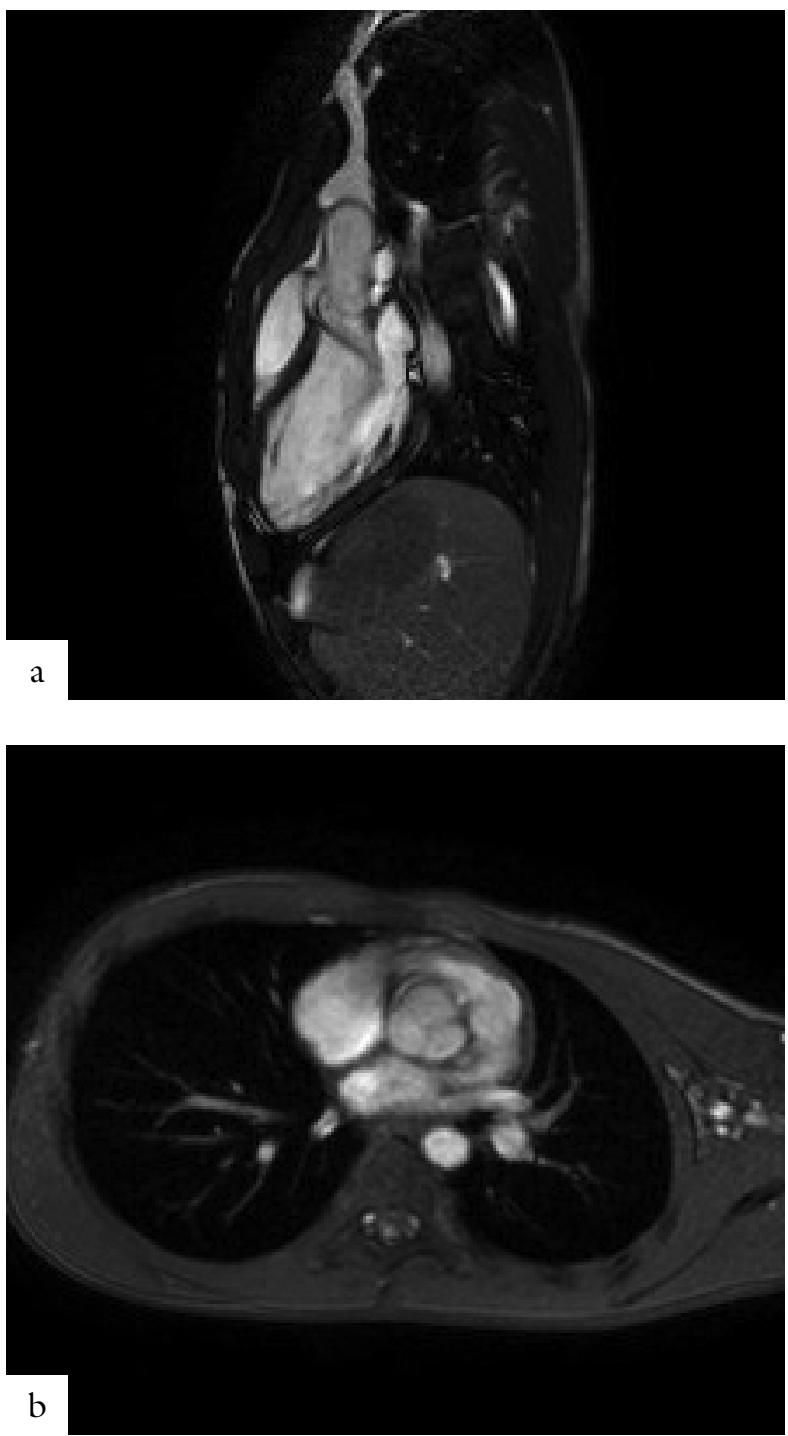

2. ábra

Preoperatív MR-vizsgálat. a)-b) A tunnel és az aortabillentyú viszonya látható

falmozgászavar nem volt, mitralis, tricuspidalis, pulmonalis insufficientia nem volt kimutatható, IVS/BKF: 5/6 $\mathrm{mm}$, Ao/Bp: 30/27 mm, aortagyök: $20 \mathrm{~mm}$, háromtasakos aortabillentyú volt látható, centrális aortainsufficientia nem volt, aorta-bal kamra tunnel jet szélesség: 8 $\mathrm{mm}$, progrediáló regurgitatio). A morfológiai képet a 3D echokardiográfiás (1. ábra) és az MR-vizsgálat (2. ábra) megerősítette. A fenti adatok alapján mútétet indikáltunk.

A mútét során (2014. szeptember 23.) median sternotomia, extracorporalis keringés, véres cardioplegia védelmében haránt irányban megnyitottuk az aorta ascendenst. A háromtasakos billentyü ép volt. A jobb coronariás tasakban, a jobb coronariás szájadéktól medialisan észlelt 6-8 mm-es szájadékát a tunnelnek autológ pericardiumfolt rávarrásával zártuk (3. ábra). Az intraoperatív TEE-vizsgálat a tunnelen keresztüli kóros áramlás megszüntét mutatta, centrális aortainsufficientia nem jelent meg, falmozgászavar nem volt. A beteg keringése stabil volt, a mútét napján extubálás történt. A posztoperatív szakban pericardialis folyadék miatt igényelt gyógyszeres kezelést. A beteg a 14. posztoperatív napon otthonába távozott.

Négy hónapos kontrollvizsgálaton panaszmentes volt, gyógyszeres kezelést nem igényelt, a szív felett zörej nem volt hallható. Echokardiográfia 3DE (Philips IE 33) során residualis aortainsufficientia nem volt detektálható, normális falmozgásokat és kamrafunkciókat észleltünk. Aortaascendens-tágulat nem volt (1. ábra).

\section{Megbeszélés}

A betegség eredete tisztázatlan. Több elmélet ismert (in utero sinus Valsalva-aneurysma-ruptura, in utero cystamedia-necrosis, aberrans, atípusos arteria coronaria dissectio, bulbus cordis malformatio) [2], de egyik sem elfogadott. A tunnel vezethet a bal coronariás tasakból a bal kamrába, a jobb coronariás tasakból a jobb kamrába vagy a bal kamrába és a noncoronariás tasakból a jobb pitvarba. A bal coronariás tasakból a bal kamrába vezető tunnel az aorta mögött található, a jobb coronariás tasakból a bal kamrába haladó az aorta jobb oldalán fut a jobb kamra kifolyási pályáján keresztül a bal kamra irányába. Ennek a típusnak négy formáját különítik el: 1. a tunnel végig egyforma nagyságú, 2. a tunnel aorta-kam-

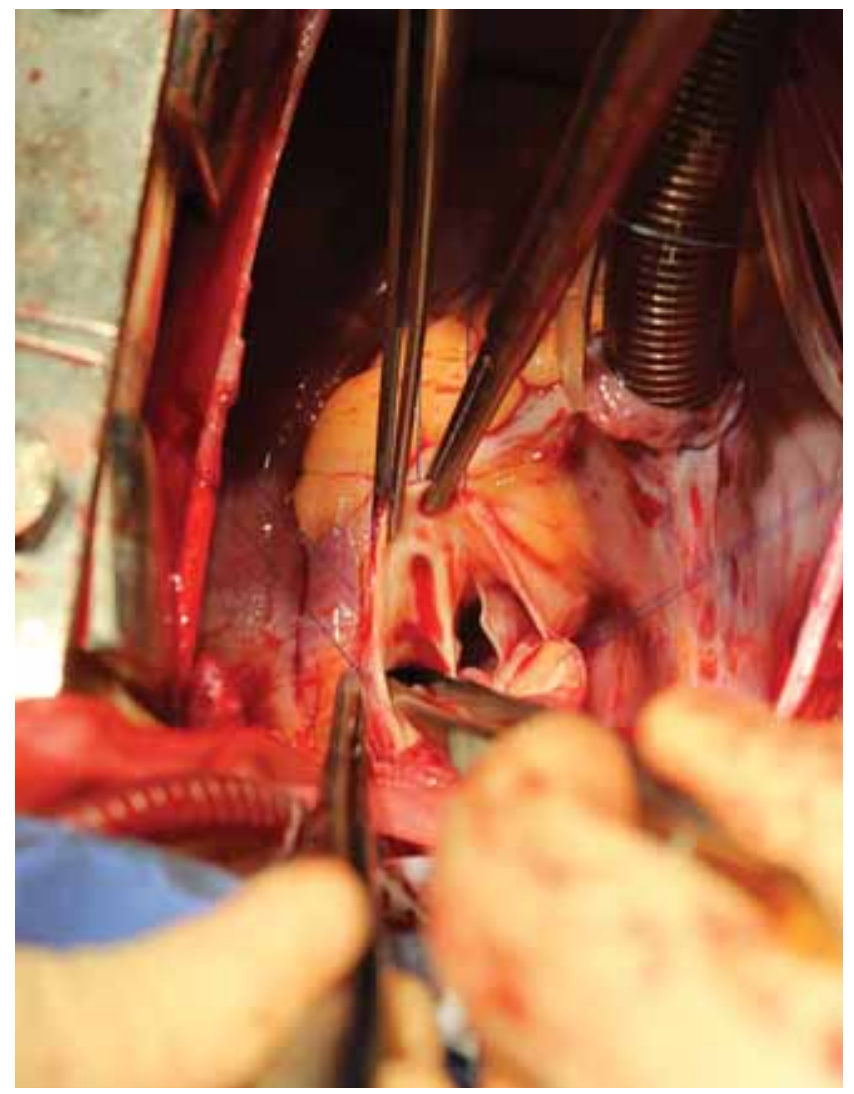

3. ábra A jobb coronariás tasakban, a jobb coronaria szájadéka alatt a tunnel szájadékában csipesz 
ra közti szakasza aneurysmaszerúen tág, 3. a tunnel kamrán belüli szakasza aneurysmaszerúen tág (ritkán a jobb kamra kifolyási pályájának szúkületét okozza [3]), 4. a tunnel mindkét szakaszán tágulat van [4]. A tunnel a jobb coronariás tasakból a jobb coronaria eredésétől medialisan, ritkán azzal közös szájadékkal ered. A klinikai tüneteket az aorta-kamra/pitvar közötti kapcsolat nagysága és nyomáskülönbsége szabja meg, súlyos esetekben már újszülöttkorban jelentkező keringési elégtelenség hívja fel rá a figyelmet [5]. Az aorta-bal kamra kapcsolat esetén a diasztolés (aorta-bal kamra) áramlás mellett „kóros” szisztolés (bal kamra-aorta) áramlás is detektálható. A fizikális vizsgálat az aortainsufficientia jeleit mutatja. Fontos elkülöníteni a kamrai septumdefektus+ aortainsufficientia, sinus Valsalva-aneurysma-ruptura, arteriacoronaria-fistula, pulmonalisbillentyü-agenesia+ Fallot IV kórképektől. Ebben vannak segítségünkre a képalkotó diagnosztikus módszerek: az echokardiográfia, CT és MR. Napjainkban szívkatéteres vizsgálat csak akkor jön szóba, ha az anatómia intervenciós zárásra alkalmasnak látszik [6]. A terápiás beavatkozást a sebészi megoldás jelenti, bár közöltek felnőttkorban felismert és gondozott esetet is, amely gyógyszeres kezelést sem igényelt [7]. Sebészi beavatkozás során extracorporalis keringésben, cardioplegiás védelemben az aorta ascendens megnyitásával keressük fel a szájadékot, amit folt rávarrásával zárunk. Ha a szájadék közös a jobb coronaria szájadékával vagy a folt felvarrása deformálná a billentyüt, akkor a tunnel kamra felőli szájadékát kell felkeresni és azt folt felvarrásával zárni. Ha a szájadék zárása nem érinti a billentyưt, a hosszú távú eredmények jók, ellenkező esetben billentyüelégtelenség alakulhat ki.

Az irodalomban közölt 130 aortatunnel-eset [8] zöme az aorta-bal kamra kóros kapcsolatát jelenti, ennek ellenére saját betegeink körében előbb észleltünk és operáltunk noncoronaris tasak-jobb pitvar, jobb coronariás tasak-jobb kamra és bal coronariás tasak-bal kamra típusú eseteket [9]. Jelen esetünk a jobb coronariás tasak és bal kamra közötti kóros kapcsolat 2-es típusát mutatta, amit a rendelkezésünkre álló modern noninvazív képalkotó eljárásokkal diagnosztizáltunk. Kiemelendő a 3D-s transthoracalis echokardiográfiás vizsgálat, amely e téren újdonságnak számít [10]. Gyermekkorban a fenti noninvazív diagnosztikai módszer alapján operált eset nem szerepel az irodalomban.
Anyagi támogatás: A közlemény megírása anyagi támogatásban nem részesült.

Szerzői munkamegosztás: H. I., B. G., K. M., K. K.: Hipotézisek kidolgozása. H. I., A. A., K. K., S. J., T. A., V. S., K. T.: Statisztikai adatok gyújtése, elemzése, megfogalmazása. H. I., K. K., B. G.: Kézirat szövegének megfogalmazása. A közlemény végleges változatát valamennyi szerző elolvasta és jóváhagyta.

Érdekeltségek: A szerzőknek nincsenek érdekeltségeik.

\section{Irodalom}

[1] Levy, M. J., Lillehei, C. W., Anderson, R. C., et al.: Aortico-left ventricular tunnel. Circulation, 1963, 27, 841-853.

[2] Fuller, S., Spray, T. L.: Aortico-left ventricular tunnel. In: Mavroudis, C., Backer, C. L. (eds.): Pediatric cardiac surgery. Fourth edition. Blackwell Publishing Ltd., 2013, 636-639.

[3] Toganel, R., Benedek, T., Suteu, C., et al.: Aneurysmal aorto-left ventricular tunnel causing right ventricular outflow tract obstruction, associated with bicuspid aortic valve. Heart Vessels, 2015, 30(1), 140-142.

[4] Hovaguimian, H., Cobanoglu, A., Starr, A.: Aortico-left ventricular tunnel: a clinical review and new surgical classification. Ann. Thorac Surg., 1988, 45(1), 106-112.

[5] Christmann, M., Dave, H., Buechel, E. V.: Prenatal diagnosis of aorto-left ventricular tunnel: introducing the 'cockade sign'. Eur. Heart J., 2015, 36(18), 1136.

[6] Chessa, M., Chaudhari, M., De Giovanni, J. V.: Aorto-left ventricular tunnel. Transcatheter closure using an amplatzer duct occluder device. Am. J. Cardiol., 2000, 86(2), 253-254.

[7] Martins, J. D., Sherwood, M. C., Mayer, J. E. Jr., et al.: Aorticoleft ventricular tunnel: 35-year experience. J. Am. Coll. Cardiol., $2004,44(2), 446-450$.

[8] Song, L., Jin, J., Tao, L.: Surgical correction of an aortico-left ventricular tunnel originating from the left aortic sinus with a left coronary artery anomaly. J. Cardiac. Surg., 2015, 30(1), 108110.

[9] Hartyánszky, I., Bodor, G., Mibályi, S., et al.: Aortic root surgeries in children performed with unusual indications. [Szokatlan javallatú aortagyök-mútétek gyermekkorban.] Cardiologia Hung., 2010, 40(3), 210-215. [Hungarian]

[10] Xia, H., Jiang, $\Upsilon$., Xu, $\Upsilon$., et al.: Transesophageal echocardiography for the evaluation of aorto-left ventricular tunnel in adults, with follow-ups. Echocardiography, 2015 Jan 2. doi: 10.1111/ echo.12870. [Epub ahead of print]

(Hartyánszky István dr., Szeged, Pécsi út 6., 6720 e-mail: hartyanszky@hotmail.com) 